\title{
System to support police driver psychological assessment for safety. Project results
}

\author{
Ewa Kuczyńska ${ }^{1, *}$, Izabela Nowicka $^{1}$, and Angelika Grześkowiak $^{2}$ \\ ${ }^{1}$ General Tadeusz Kościuszko Military University of Land Forces, 109 Czajkowskiego Str.,51-147, Wrocław, Poland \\ ${ }^{2}$ National Research and Development Centre, 47a Nowogrodzka Str., 00-695, Warsaw, Poland
}

\begin{abstract}
The objective of this article is to present the results of research designed to build a system of support for the psychological assessment of police drivers, including drivers of police emergency vehicles, as required by Polish law. Part of the research and development efforts, the project analyses the world's most recent research (commercial and non-commercial projects) which is not subject to confidentiality rules. The analysis shows that the project will help to build a functional support system. Based on modern IT technologies and part of the Police's PDTN network, the system will support the psychological assessment of police drivers, including drivers of police emergency vehicles. The system was implemented in IT network technology and can, as a result, operate directly with the Police Data Transmission Network (central server, access from any PDTN workstation) ensuring independence and security of data collection and storage.
\end{abstract}

\section{Introduction}

Every country strives to ensure that the police is professionally prepared to deliver their tasks. This is achieved through the provision of knowledge and skills and advanced technologies to support police officers with their work. One of the most significant areas of safety which requires special training is road traffic. Because it is such a key issue, many countries have dedicated traffic police services. While Poland's traffic police is part of the preventive police service, its tasks do not differ from those of other services of this type worldwide. It should be noted that traffic hazard prevention poses a significant challenge. Driver attitudes have a multi-component structure, shaped not only by the drivers themselves, but also by external factors. Therefore, it is necessary to conduct an in-depth analysis of driver behaviour to help drivers solve any risk-generating situation rationally. Theoretical models of human behaviour in a complex operator environment are designed to describe all factors, including those which activate human error. These may be psychophysical properties, social adjustment, driver attitudes, social discipline, emotional control and skills for coping with a complex task such as driving a motor vehicle. Road traffic is a complex system of actions and behaviours in a specific situation in space shaped by the man-vehicle-road relation. Driving performance consists of three aspects: physical efficiency (specified by means of medical checks); psychological efficiency (assessed in driver psychological tests); knowledge, skills and attitudes of the driver [1]. Psychological tests of drivers are designed to reduce the risk of a driver behaving dangerously and as a consequence causing an accident $[2,3]$.

\section{General project description}

In 2015 following Poland's Chief of Police statement on the importance of road safety knowledge, a new project was developed entitled "Elaboration of a support system for psychological tests of police drivers - PolDrive". The objective of the project is to create a support system for psychological testing of police drivers, including drivers of police emergency vehicles, in accordance with Poland's legal regulations. Once developed, the new solutions (system) will operate in an IT network technology to ensure direct cooperation with the Police's Network of Data Transmission, the basis for independence and security of data collection and storage. As a result, it will be possible to carry out research without having to use additional equipment with just a properly configured computer set. New devices will be available for calibrating a methodology for measuring reaction times, assessing intellectual and psychomotor skills and personality factors using effective and reliable tools. The project is managed using PRINCE2, a methodology which helps to control variables and achieve project efficiency such as costs, deadlines,

\footnotetext{
* Corresponding author: e.kuczynska@,wspol.edu.pl
} 
quality, scope, risk and benefits. In this methodology, project management is based on the principles of constant business validity, use of experience, defined roles and obligations, phase management, management with the use of tolerance, focus on products and adjustment to project conditions. The steering committee is responsible for taking strategic decisions within the project. It consists of representatives of all project consortium members. In addition, the Police Academy in Szczytno asked the project manager (Polish Police) to appoint the school's representative to become a member of the committee. The steering committee is run by its chairman who has final responsibility for the project. The other members form an advisory body. To help the project manager with project management, as required in the methodology, an operational manager was employed, who holds a Prince2 Foundation certificate, extensive knowledge and rich experience in project management in the methodology.

\section{Selected legal issues}

The structure of the project is not random. Firstly, it contains an analysis of the most recent worldwide research and development works (commercial and non-commercial projects) which are not subject to confidentiality rules. The project will help to elaborate a modern IT system to support psychological tests for police drivers, including drivers of emergency vehicles. The system will meet all legal and quality requirements expected of psychological diagnoses. It will be equipped with standards and help to optimize the accuracy of diagnosis. Documents had to be reviewed. To analyse the documents, direct observation was used to analyse legal acts, at the national, international and European Union level. The study also looked at the the rulings of the European Union's Court of Justice, Constitutional Tribunal of the Republic of Poland and the Supreme Court of Poland. The method of analysing documents allowed for the use of doctrinal sources. It was applied in the research of dogmatic nature. The views of representatives of individual fields of science were acknowledged with regards to matters related to the problem of creating a fully functional system that is one which fulfils the requirements of the highest, IX level of readiness of the main project also in legal terms.

An assumption was made that police drivers are bound by the same traffic rules as any other road user (Act of 20 June 1997 on Traffic Code, Journal of Laws 2012.1137 consolidated text). The Polish law defines a driver (Article 3 of the Act of 5 January 2011 of Journal of Laws of 2015, 155 consolidated text) as a person who has reached the required age, has the necessary physical and psychological capability and meets one of the following conditions:

- has the skills to drive a vehicle in a manner which does not constitute a threat to safety, hinder road traffic or put anyone at risk of damage, holds an appropriate document confirming their license to drive a vehicle;

- has had driving lessons;

- has passed a state examination.

1. A vehicle driver may also be a person who had training under initial qualification, accelerated initial qualification, supplementary initial qualification or supplementary, accelerated initial qualification, as specified in section 7a of the Act of 6 September 2001 on road transport (Journal of Laws of 2013, item 1414, as amended) and is capable in physical and psychological terms.

2. A person with a physical disability may be a driver provided that they have been cleared by a doctor to drive a vehicle.

3. A person who is 18 and more is not required to hold a document licensing them to ride a bicycle, bike cart or horse-drawn vehicle.

The Act specifies the criteria for emergency vehicle drivers saying that (Article 106 (1) a person may drive an emergency vehicle provided that they:

1) are above 21 years of age;

2) hold a driving license appropriate for the type of vehicle category;

3) have obtained a statement:

a) from a doctor clearing them to drive emergency vehicles,

b) of a psychological assessment stating that there are no psychological reasons why they should not drive a vehicle,

4) have completed a course for emergency vehicle drivers,

5) are licensed to drive an emergency vehicle.

4. Article 1 (1) does not apply to police officers, as specified in Article 8 (3).

5. Article 1 (4) does not apply to officers of the National Fire Service, Border Guard, Government Protection Bureau, Prison Service and Road Transport Inspection and Voluntary Firefighters.

The above law makes it clear that emergency vehicle drivers must produce a statement that they are fit to drive both mentally and health-wise. This happens when drivers apply for permission to drive emergency vehicles. To be considered is also the fact that under specific circumstances the tests should be conducted if it is not clear whether a given person is fit for the job. Psychological driver tests are diagnostic. There are special diagnostic tests for persons from a risk group who have been referred for a test under the Traffic Code because they have been caught driving under the influence of alcohol, exceeded the limit of penalty points or committed a road traffic offence. The objective of these tests is to diagnose whether there is a link between the driver's behaviour (causes 
of a road accident) and their capacity and/or personality as recorded in the test result. Once established, the relation forms the basis for predicting the driver's future behaviour in road traffic [4].

Conducted for the purposes of the project, the analysis of legal acts presented how assessments are to be made of intellectual performance, psychomotor skills and personality of motor vehicle drivers. This has placed psychological tests in the system of Polish law, the point of departure being the fact that someone drives an emergency vehicle under the influence of alcohol or other substances. Furthermore, it will enable swift management of test documentation and feedback for the persons tested. Transfer of technology will also be possible for civil use which should have an impact on better road safety. Secondly, the resources of the science and business consortium and the potential of partners cooperating with national scientific-didactic centres, their knowledge and experience will help to deliver unique and highly functional technological solutions. The work will also contribute to the development of science and technology. Furthermore, there are plans to use touch screens. While they are an innovative tool for registering the reactions of the people tested when exposed to simple and complex test stimuli, the level of errors made during the registration is unknown and is not assessed by equipment producers as a standard procedure. Before touch screens are used, a new technology must be developed to assess and eliminate errors caused by how the reaction is recorded. An innovative solution to the problem is a calibrator of methodology of reaction time tests.

\section{Results of project activities}

With the completion of the first stage of tests, the online platform is ready to show a prototype and model of psychological variables of test participants. The online platform operates databases which will register all psychological tests involving police drivers. The user (psychologist) who conducts a test can introduce and edit data of the tested persons, select tests which the test participant is to take and generate documentation which is both required by law and functional. Furthermore, the psychologist has tools for the analysis of results, generation of descriptions and support for judicial decisions. The test application is a programme installed on a computer terminal of a tested person who will carry out the tests, and subsequently send the results to a server. Next, using an online platform, a psychologist will upload and process data for analysis. At the initial stage all IT tools which are part of the above functionalities have been configured and tested in laboratory conditions. The second result of this stage is the psychological part. On the basis of the literature, interviews with experts and project authors' experiences a psychological profile of a police driver was defined. Significant variables from the area of intellectual and cognitive functions were gathered and defined as well as personality and efficiency factors. Furthermore, the theory part of the test workbook for system users was elaborated. The work has also produced test procedures (algorithms, tasks and instructions) in the form of programmes performed by the testing application. The scope of tested variables covers perception processes, attention, understanding and anticipation processes, level of emotional and social maturity [5], fastness and accuracy of reactions and eye-hand coordination. The make-up of indicators for individual tests was also elaborated. As a measure of diagnostic accuracy, the questionnaire DBQ was applied [6].

Adequate technical documentation was performed for the new software.

Project duration was planned for 36 months and the first stage ended after 24 months. The result was the launch of the diagnostic system which is fully prepared for testing. The second stage consisted of verifying and optimizing the accuracy of the effects. Moreover, prior to the completion of project works, the system was supplemented by norms for emergency vehicle drivers and modules for documentation management, testing and creation of automated feedback for test participants, including the results, advice and recommendations. It is suggested that the solution should expand the functionality of data analysis methods, and elaborate a uniform driver data base and create an expert module for supporting judicial and personal decisions. It is expected that a fully functional system will be implemented meeting requirements of the highest level of technological readiness.

In line with the Project assumptions, under task 1 of stage III, a set of tests elaborated in stage II underwent empirical testing. Tests were conducted among Police Academy in Szczytno police officers, post-graduate students and I and II degree full time and part-time students of the Faculty of Interior Security. Tests were elaborated by the project consortium's member company ALTA Sp. z o.o. in Siemianowice Śląskie. The tests were designed to specify psychometric parameters, including reliability and accuracy of indicators. This stage also covered standardization of testing. Instructions and interactive exercises were verified for their transparency and comprehensibility. On the basis of an analysis of the difficulties faced by the test participants while filling out the tests, further modifications of procedures will be made. As well as conducting traditional psychometric analyses, an analysis of test results on the basis of IRT (Item Response Theory) was conducted, where possible. This method helps to increase the reliability and accuracy of the results against classic psychometry on the basis of corresponding entry data. A group of police drivers conducted the tests designed as an experiment. At the same time, tests were conducted using selected methods that are already known in transport psychology. The data were analysed for the discrimination power of test items. An internal compliance analysis of the tests was also conducted. As a result, the experimental versions of the methods were finalised and optimized to ensure that the necessary information can be obtained in the shortest possible time of an individual test. Validation tests were 
carried out in a group similar to the target group. Due to the duration of the procedure and the organizational possibilities the test was divided into two stages.

\subsection{Stage I}

Testing for the assessment of intellectual functions and personality. This examination was conducted as an anonymous and coded group test (it is necessary to link the results of different tests carried out by the same person). Testing time: about 60 minutes. Size of the group - 120 people.

Before starting the tests for the assessment of intellectual functions and personality, each participant had to answer a few questions about themselves. The answers helped to develop a description of the experiment to the working standards of the tests. In the first stage, 120 people took part in the examination. $68 \%$ of them were men and $32 \%$ were women. The group of participants consisted of $24.16 \%$ of people aged up to 30 years old and $75.84 \%$ of people aged between 31 and 50 . No person over 51 years old participated in the examination. The participants differed as regards the number of years of holding a driving license. The smallest group included people who have had a driving license for not longer than two years $-0.83 \%$. The largest group included people who had had a driving license for over 5 years $-88.34 \%$. The remaining $10.83 \%$ of people are those who have had a driving license for a period from three to five years. The participants were also characterized by different length of experience of driving a car. The smallest group included people whose driving experience did not exceed two years $-3.34 \%$. The largest group included people whose driving experience is longer than five years $-84.17 \%$. The remaining $12.5 \%$ of people are those whose driving experience is between three and five years.

During the examination, after each subtest of the test in the field of intellectual efficiency, the subjects were asked evaluation questions in which they had to assess the intelligibility and readability of elements of each subtest - instructions, test phase and specific tasks. After finishing all the subtests, the subjects were asked questions about the level of mental strain, efficiency and frustration experienced by them during the test. Also after completing the personality test they were asked evaluation questions, in which the subjects had to assess the intelligibility and readability of instructions and content of questions. Additionally, there will be questions about the level of mental strain, efficiency and frustration experienced by the subject during the test.

The intellectual efficiency tests consisted of 4 subtests: 1 . Abstract tasks 2. Spatial tasks 3. Basic numerical tasks 4. Advanced numerical tasks. The participants were asked to evaluate the intelligibility and readability of the instructions, the phase of exercises and specific tasks in each of the subtests.

In the validation tests, stage I tests were conducted in the area of personality and intellectual efficiency. To properly save the results necessary to calculate the psychometric properties of the tests, a database was designed which enables data export in the required form.

\subsection{Stage II}

Testing in the field of psychomotorics and anticipation. According to the assumptions adopted in the project, it was necessary to conduct individual examinations. The test was anonymous and coded (it is necessary to link the results of different tests carried out by the same person). Testing time: 60 - 90 minutes. Size of the group - 35 people. Before starting the tests for the assessment of intellectual functions and personality, each participant had to answer a few questions about themselves. The answers helped to develop a description of the experiment to the working standards of the tests. In the first stage, 35 people took part in the examination $-66 \%$ of them were men and $34 \%$ were women. The participants differed as regards the number of years of holding a driving license. The smallest group included people who have had a driving license for not longer than two years $-2.86 \%$ (only women). The largest group included people who have had a driving license for over 5 years $-82.86 \%$. The remaining $14.29 \%$ of people are those who have had their driving license for a period from three to five years (only men). The participants were also characterized by different length of experience of driving a car. The smallest group included people whose driving experience did not exceed two years $-5.72 \%$. The largest group included people whose driving experience is longer than five years $-77.14 \%$. The remaining $17.14 \%$ of people are those whose driving experience is between three and five years. During the examination, after each test in the field of psychomotor and cognitive ability, the subjects were asked evaluation questions in which they had to assess the intelligibility and readability of elements of each test - instructions, test phase and specific tasks. In addition, after the completion of each test, the subjects were asked to rank the level of mental strain, effort and work, pressure, efficiency and frustration experienced by them during the test, on a scale of 1 to 20 . The calculated value is the median (median value - the value of the feature in an ordered series, with the same number of observations above and below) of results of the responses given by the subjects.

Psychomotor ability tests that were performed by the subjects are as follows:

- Simple reaction time test

- Choice reaction time test

- Visual-motor skills test

- Two-dimensional visual-motor skills test 
Cognitive ability tests, that were performed by the subjects, are as follows:

- Perceptiveness and attention test

- Anticipation test

In the validation tests, stage II tests were conducted in the area of personality and intellectual performance, psychomotor and cognitive ability. To properly save the results necessary to calculate the psychometric properties of the tests, a database was designed which enables data export in the required form.

\section{Conclusion}

The system described above will be implemented in the Polish Police and will facilitate independent psychological examinations of drivers required by law. The tests will be conducted by the in-house staff of police psychology laboratories without having to incur additional costs related to commissioning psychological examinations outside the Police. The system's target users include authorized psychologists from Voivodship Police. As a result of the project, by the end of 2018, the "Poldrive" examination system will reach the operating level and will be ready for conducting empirical research in a real environment.

The research has been carried out under the development project of Police Academy in Szczytno, entitled "Elaboration of a Support System for psychological tests of police drivers", No. DOB-BIO7/20/01/2015 implemented by a scientific consortium, financed from the resources of the National Research and Development Centre under contest 7/2014 for projects in the scope of scientific research or development works towards national defence and security.

\section{References}

1. J. Bąk, D. Bąk-Gajda, Psychological factors in road safety (in Polish), Eksploat. i Niezawodn. 3 (2008)

2. M. Ucińska (ed.), Metodyka przeprowadzania badań psychologicznych w zakresie psychologii transportu (in Polish) (ITS, Warsaw, 2015)

3. E. Odachowska (ed.), Badania kwestionariuszowe w psychologii transportu. Przegląd stosowanych metod (in Polish) (ITS, Warsaw, 2015)

4. Psychological tests of drivers as a form of action for the safety and occupational health of drivers. Material for the meeting of the Labor Protection Council at the Sejm of the Republic of Poland on October 21, 2008 (2018)

5. A. Łuczak, A. Tarnowsk, Artefacts of questionnaire-based psychological testing of drivers (in Polish), Med. Pr. 65 pp. 373-385 (2014). doi:10.13075/mp.5893.2014.036

6. M. Niezgoda, T. Kamiński, M. Kruszewski, A. Tarnowski, Self-reported drivers' behavior: an application of DBQ in Poland, J. Kones Powertrain Transp. (2013) 